\title{
What Still Matters in a City. The COVID-I 9 Pandemic Offers a "Teachable Moment" Illustrating that Public Spaces Must Simultaneously Connect us, and Protect us too
}

Michael Mehaffy

Ax:son Johnson Foundation, Sweden

michael.mehaffy@gmail.com

Tigran Haas

KTH Royal Institute of Technology, Centre for the Future of Places, Sweden

tigran@kth.se

Peter Elmlund

Ax:son Johnson Foundation, Sweden

peter.elmlund@gmail.com

\begin{abstract}
Various commentators have sought to assess the long-term impact of the COVID-19 pandemic on urban form and public space, with predictions ranging from "the end of urban density," to a new impetus for auto-encapsulated sprawl, to exacerbation of the effects of urban inequality, to an explosion of digital surveillance, to a return to relative normalcy with new protective strategies. Here we tease out a more basic lesson about public space: that it is far from one amorphous thing, but it has both connective and protective characteristics. Its structure has a profound impact upon the life of the city and the health and well-being of its residents. Furthermore, it is up to us, as practitioners at the interface of science and policy, to chart the very real choices emerging for a better generation of public space and urban form.
\end{abstract}

Keywords: COVID-19, pandemic, public space, sociable distancing, place network

To cite this article:

Mehaffy, M., Haas, T., Elmlund, P. (2020). What Still Matters in a City. The COVID-I 9 Pandemic Offers a "Teachable Moment" Illustrating that Public Spaces Must Simultaneously Connect us, and Protect us too, The Journal of Public Space, 5(3), 3I-38, DOI I0.3289I/jps.v5i3.1378

This article has been double blind peer reviewed and accepted for publication in The Journal of Public Space. 


\section{Introduction}

Since their beginnings, cities and towns have been shaped by pandemics as well as other stressors (war, fire, weather and so on). What has happened to the human race beginning in late 2019 is certainly historic, but hardly exceptional - except perhaps in the memories of those alive today. It follows that the impacts of this pandemic are likely to be significant but not novel, historically speaking. In fact, this episode may only heighten the urban challenges and choices we have already faced. At its best, it may prompt us to tease out factors that we left much too vague and ill-considered before.

In the literature of urbanism, planning and urban policy, the pandemic has brought out a number of intriguing assessments of long-term impacts, as a survey of the early literature reveals. Perhaps most notable is a re-assessment of the benefits of urban density and population size, previously described as key aspects of urban sustainability (Desai, 2020) but now identified as key corollaries of high transmission rates (Rocklöv and Sjödin, 2020, Stier, Berman and Bettencourt, 2020). Others foresee a renewed phase of low-density, cardependent sprawl (Kotkin, 2020) while still others note the continued negative and inequitable impacts of sprawl (Litman, 2020) and the further exacerbation of economic and other urban inequalities (Bonaccorsi et al, 2020). Others see an acceleration of big data and Smart city technology, with its associated implications for data privacy and surveillance (Inn, 2020). Still others see a resumption of megacity high-rise business as usual following relatively modest retrofitting (Acuto, 2020).

Here, rather than try to prognosticate - mindful of Yogi Berra's advice that "it's difficult to make predictions, especially about the future" - we ask a more basic question about this episode as a "teachable moment." What does the pandemic reveal about the nature of cities, and especially, the nature of their public spaces? What does it reveal about our choices ahead, and their potential impacts?

Following are our conclusions:

I. It is not density in the abstract, but the patterns of density that matter most for both contact and safety. Different urban forms at the same density can have very different connective and protective properties. The famous diagram below, by the UK's Urban Task Force, shows three very different urban forms with exactly the same density, 75 units to the hectare ( 30 units to the acre). We added the red lines to show that the connective properties are also radically different in the three examples. In the "tower in the park" model to the upper left, there are "choke points" in lifts/elevators, lobbies and entrances, that force people into close contact. In the rowhouse form in the middle, the points of connection are much more diffuse, although there are still ample public spaces that provide contact as desired while maintaining social distancing. In the perimeter block model to the lower right, a series of smaller lifts/elevators and a greater number of entries also provides a greater range of connectivity while affording social distancing.

2. It is perfectly possible to achieve safe social distancing within many different kinds of public spaces. In addition to the overall urban form, other structural features of both buildings and public spaces can provide for social distancing while also allowing social contact - what we call "sociable distancing." The key requirements are connective structures that provide partial enclosure and separation while also providing partial connectivity and contact, controllable by the users. History is full of examples of these "connective spaces," which serve to connect public spaces more effectively to private ones. They include stoops, balconies, porches and other "lowly" urban elements whose importance as protective connectors should finally be recognized. 


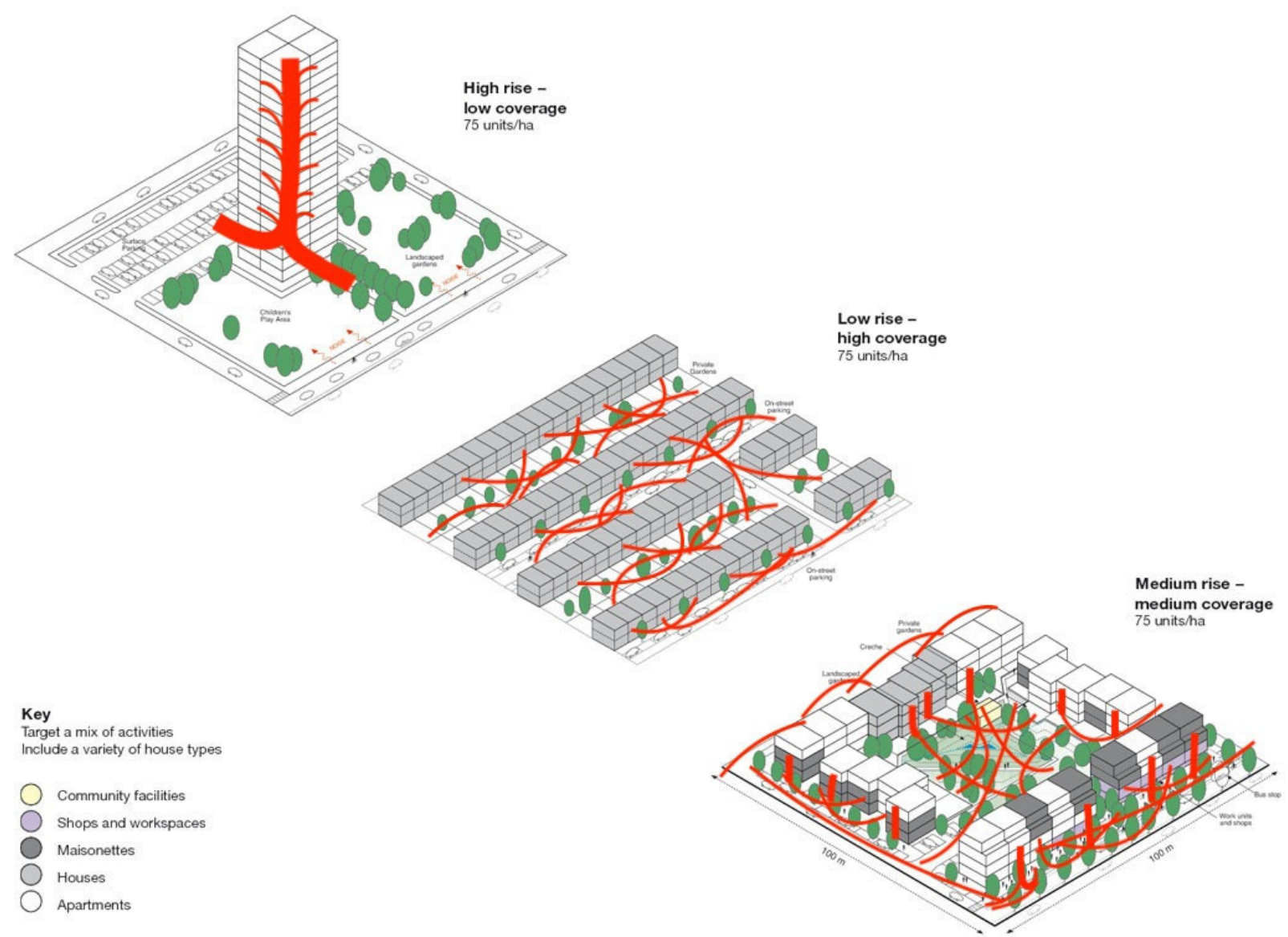

Figure I. Illustration from the UK Urban Task Force (1999) demonstrating that the same density can take very different urban forms (illustration modified by the authors).

3. What matters in public space is not only its capacity to connect us to one another within it, but also to afford controlled protection, and to connect us to other private spaces and the greater protections they afford. As our work has demonstrated, public spaces have an essential room-like structure of partial enclosure and partial openness, providing controlled connectivity to their occupants (Mehaffy, Elmlund and Haas, 2019). Furthermore, they are embedded within a web-network of more private room-like spaces, including literal rooms. The porch in the example above, together with the sidewalk, the landing, and the adjoining private living room, are all part of this system or "place network." Such structures can be observed in abundance in thriving streets and urban spaces, including the example of the London streetscape shown below.

4. This capacity of public spaces to protect as well as to connect means that these spaces are not static, but evolving and transforming in response to user needs and choices. Different populations will of course have different needs for protection and contact (e.g. the elderly, children, people in environments they perceive as dangerous) and the best urban spaces afford them a measure of choice and control - either in selecting from a suitable range of protective or connective spaces, or in actually rearranging the spaces (moving chairs, occupying tables, putting out boundary-marking devices such as picnic blankets, etc.). (Mehaffy, Elmlund and Haas, 2019) 


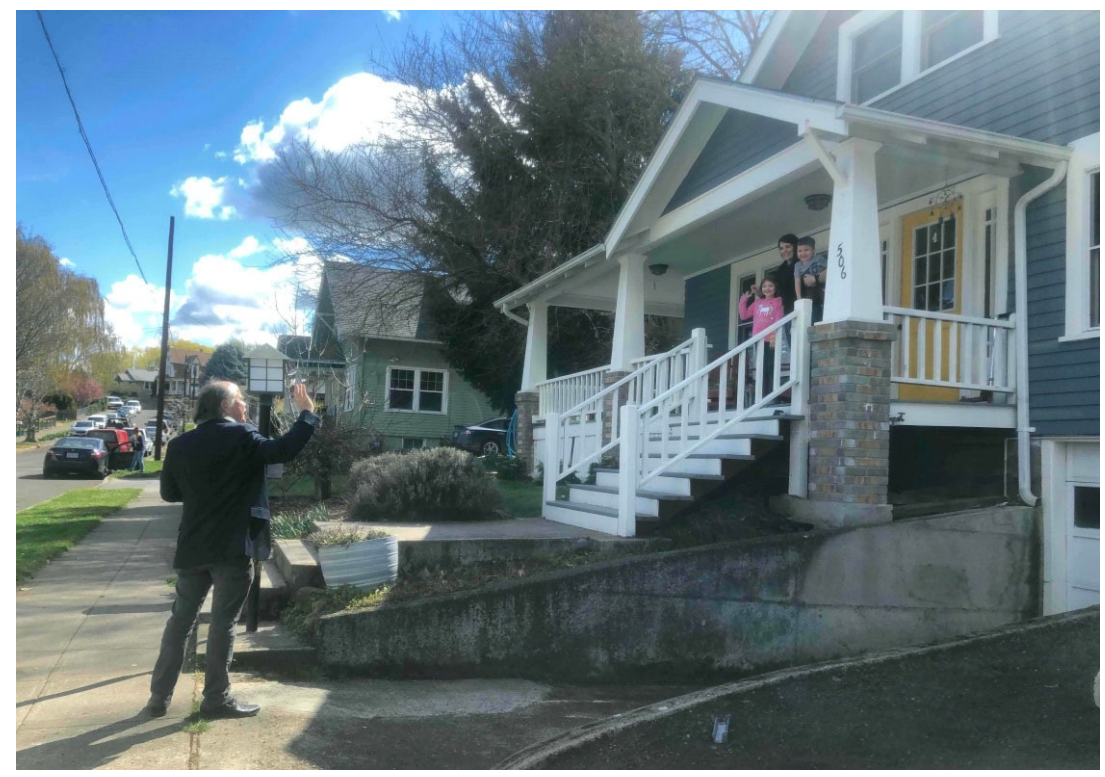

Figure 2. One of the authors in a "sociable distancing" visit with his daughter and grandchildren. Photo: The authors.

5. In addition to fully public spaces, the "third places" to which they connect are also critically important for urban vitality - and the impact of their absence is painfully evident during the COVID-I 9 pandemic. Third places, described notably by Ray Oldenburg (2002), include more enclosed public spaces, like dog parks and community gardens, and also more private spaces that offer public accommodations, like cafés and restaurants. However, as Oldenburg makes clear, to function optimally, any "third place" must be free or relatively inexpensive to enter, it must be easily accessible from home or work on a daily basis, and, less tangibly, it must be perceived as welcoming to all. As Oldenburg and others have pointed out, such third places are crucial to a community for a number of reasons. They are firstly distinctive informal gathering places, secondly, they make the citizen feel at home, thirdly they nourish relationships and a diversity of human contact, fourthly they help create a sense of place and community, and finally, they invoke a sense of civic pride. There is additional evidence that third places are important locales for the formation of social "weak ties" and the generation of social capital (Jeffres et al., 2009). They may also be important sides of so-called "knowledge spillovers" and the generation of city innovation and economic development (Roche, 2019).

At a deeper level, public and private spaces are not simply the physical structures that are conceived and arranged by planners and designers, but the places that people identify, and that are, to a large degree, socially produced and modified. A number of writers have described this more tacit aspect of place networks, including Edward Soja (1996) and Henri Lefevbre (1974) in their description of open-ended, undefinable, fluid, and endlessly complex "thirdspace" (Soja's term). Perhaps more relevant for our discussion is Bruno Latour's "actor-network theory" (1996) in which people, their spaces, their institutions, and their conceptions, all interact within a system, in which the physical, the social and the psychological must be seen as part of one transforming structure. 


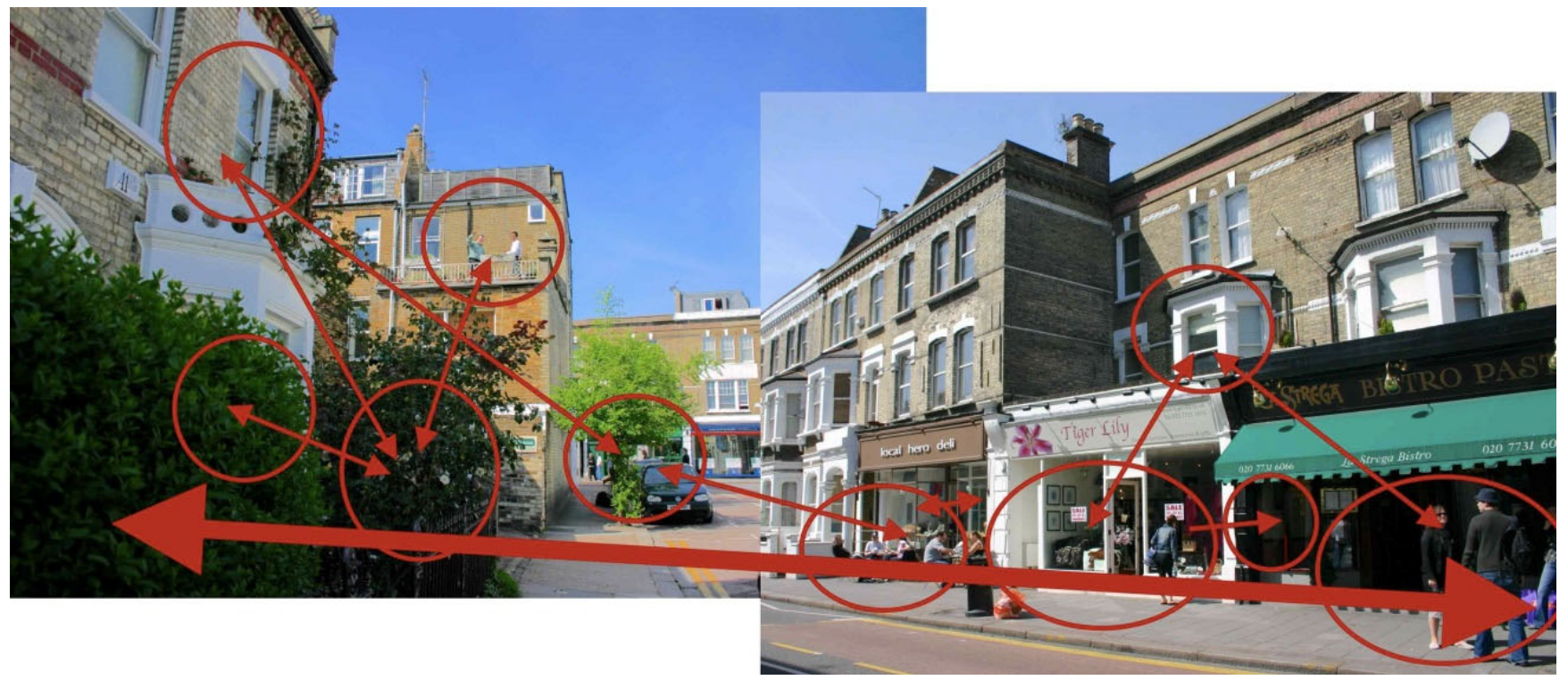

Figure 3. Composite photo of a fairly ordinary London street nearby where one of the authors happened to live. A close examination of its "place networks" reveals a dizzying system of room-like spaces, from the most private actual rooms (bedrooms etc.) to the most public room-like spaces leading to the street (sidewalk café groups, etc.) and many different kinds of indoor and outdoor spaces in between. Photo: the authors.

\section{Rooms in a building...}

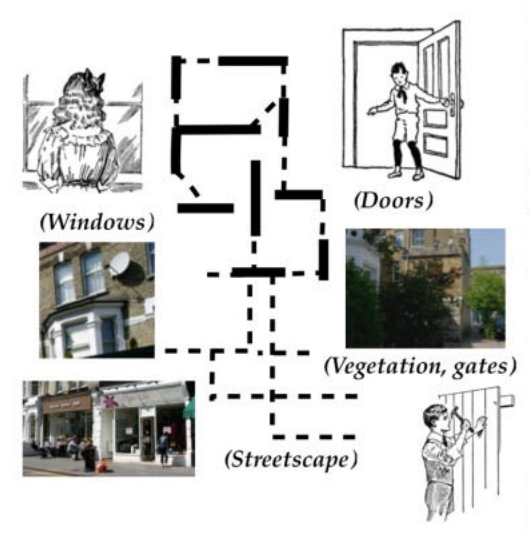

\section{"Rooms" outside a building...}
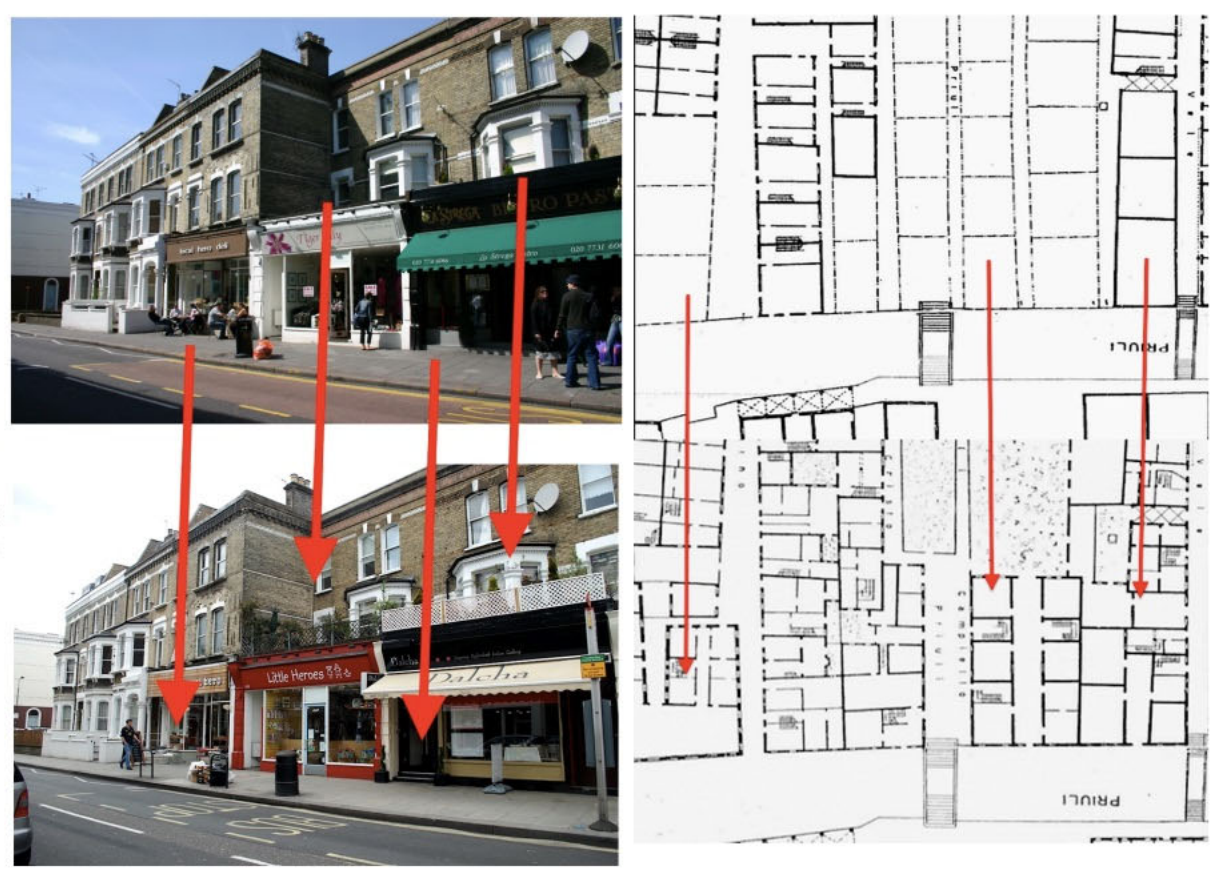

Figure 4. We are constantly co-producing and transforming our room-like public as well as private spaces, our "place networks," over many scales of time. We open windows, close doors, remodel spaces, and make longer-scale transformations, like the changes over five years in London (centre) and over a century in Venice (right).

In all of these examples, what matters is that people are interacting with their public and private spaces, modifying them, transforming them, making them more or less connective, and more or less protective. The mental aspects define and constrain the physical, but 
the reverse is also true. Moreover, this transformation goes on at the scale of hours or days (open a door, close a window, set out a picnic blanket) or years or centuries (remodel a home, build new buildings, transform a city) - as the illustration below demonstrates.

6. When it comes to urban space and density, something like a "Goldilocks principle" applies. Too many of the discussions of urban density seem to only assume either extreme high density in the cores, or extreme low density at the edges. The best examples from history demonstrate that there is a distribution of sizes and densities of spaces, buildings, neighbourhoods and cities, forming "polycentric" regions. This is true even in smaller areas, like informal settlements - which, at their best, also self-organize into patterns of public and private spaces, with a complex pattern of density gradients (Mehaffy, Elmlund and Haas, 2019). While density as an isolated attribute can certainly be beneficial, it does not follow that very high densities are only beneficial - or in the wake of the COVID-I9 pandemic, only harmful. As we have seen, the real question is how density can be achieved selectively to meet particular goals, within particular structures of connectivity. We need to do a better job teasing out the actual working dynamics behind "density" and other simplistic abstractions. Of course, we also need to recognise that it is not only density that matters, but the pattern of uses and activities, and their mixed distribution (Mehaffy, 2015)

7. The pandemic has highlighted a number of severe weaknesses in our current urban condition. We have witnessed the extreme degree to which our systems have poor resilience, and far from optimum conditions of equity and sustainability. Instead of the features of "ecological resilience" needed - redundancy and diversity, a mix of finegrained scales, inter-connected web-network structures, and the capacity for selforganization - our systems, including our systems of settlement, are characterized by the "engineered resilience" of long, narrow supply chains, large, "too big to fail" systems, hierarchical, "tree-like" structures, and "top-down," command-and-control approaches (Mehaffy and Salingaros, 2017). Instead of an optimum mix of equitable opportunity and access, too many cities and regions continue with pockets of deprivation and poverty, placing a drag on the viability and sustainability of their entire regions (Bettencourt, 20/3). Instead of the natural capacity of urbanism to achieve high quality of life with low resource consumption (characterised by walkability, compactness, optimal distribution of destinations, efficient transport, etc.) we are overly dependent on unsustainably high resource consumption urban systems that utilize automobiles, segregated functions, lowdensity sprawl, tree-like organization, and other characteristics of a "depletion economy" - very far from what is needed for a sustainable "repletion economy" (Mehaffy and Salingaros, 2017; Mehaffy, 20I2).

8. There is a corollary for social resilience. As the work of Klinenberg (200I) and others have shown, residents depend upon a web-network of relationships to cope with stressful events. Crucially, these web-networks are formed and maintained within public spaces, and the adjoining private and group spaces to which they connect. As Klinenberg observed in his famous study of the Chicago heat wave of 1995, the key difference in higher survival rates for some residents "turned out to be the sidewalks, stores, restaurants, and community organizations that bring people into contact with friends and neighbours" (Klinenberg, 20I3).

9. Medical science has provided a very helpful lens on our urban professions. As with medical science, the first requirement is to have a clear picture of the nature of the challenge before us - a point famously made by Jane Jacobs in her last chapter of The 
Death and Life of great American Cities (196I). Also, as with medical science, there is a necessarily iterative relationship between the research science and the practice. With a useful model of cities supplied by the science - analogous perhaps to the germ theory of infections - we can recognize the structural changes needed to promote health and wellbeing, following the evidence, and using an iterative, self-correcting, learning process.

Moreover, at its best this process learns from recent experience as well as the accumulated experience of centuries. It is capable of moving past pseudo-scientific nonsense and failed ideas, into a more responsive application of useful ideas about our environmental challenges.

\section{Conclusion}

We see that public spaces are far from amorphous realms where people mix haphazardly. Rather, like private rooms, they also have a clearly articulated structure of boundaries and controlled gateways, albeit one that is in constant transformation, and continuously shaped by social and psychological forces as much as physical ones. Nor do public spaces constitute a wholly separate realm from more private spaces, except in pathological forms of urbanism. In the best and most vital streets and neighbourhoods, public and private spaces form a complex web-network of intricate spatial relationships, with their boundaries and openings forming membrane-like structures, whose connectivity is modulated by users and by other complex forces.

In this sense, public spaces are of the essence of cities, and healthy public spaces are of the essence of healthy cities. We can intervene in this web-like structure to make them more equitable, more accessible to all, more optimal, more ecological, and more vital. But we can only do so having first understood their tissue-like qualities, and the ways we can, like a good surgeon, operate on this "tissue" to enhance health and cause minimal further damage. In particular, we must understand at the outset that enclosure and seclusion are not by themselves the enemies of connectivity and openness, but on the contrary, their necessary close partners. It is only when one or the other aspect of urban space goes wholly out of balance - when we create fortifications, privatizations and gated communities at one extreme, or nebulous, swoopy "no man's lands" at the other - that we set up our cities for decline, for the squandering of resources, for growing pollution and emissions, for growing human misery, and for ultimate catastrophe.

On the other hand, as Jacobs also pointed out, cities do contain within them the seeds of their own regeneration - if we apply the knowledge and skills necessary to promote their diversity and health. The COVID-19 pandemic has done us an inadvertent favour by throwing this situation into high relief, if we will look. Our choice is stark: we can continue to let the revealed pathologies of our cities fester out of control - or we can commit to putting the lessons of this historical moment to work for us.

\section{References}

Acuto, M. (2020). COVID- 19: Lessons for an Urban (izing) World. One Earth 2(4) 2020, pp. 317 319. Accessed at https://www.sciencedirect.com/science/article/pii/S259033222030I55X

Bettencourt, L. M. A. (20I3). The kind of problem a city is. Santa Fe Working Paper 20I3-03-008. Santa Fe: Santa Fe Institute. Available on the Web at https://sfi-edu.s3.amazonaws.com/sfiedu/production/uploads/sfi-com/dev/uploads/filer/fa/f6/faf6I4I 8-fc4f-42d5-8c28-dfI I 97a390| I8/I303-008.pdf. 
Bonaccorsi, G., Pierri, F., Cinelli, M., Porcelli, F., Galeazzi, A., Flori, A., and Pammolli, F. (2020). Evidence of economic segregation from mobility lockdown during COVID-I9 epidemic. Working paper, Politecnico di Milano. Accessed at https://arxiv.org/pdf/2004.05455.pdf.

Desai, D. (2020). Urban Densities and the Covid-19 Pandemic: Upending the Sustainability Myth of Global Megacities. ORF Occasional Paper, 244(4). Accessed at https://www.orfonline.org/wpcontent/uploads/2020/05/ORF_OccasionalPaper_244_PandemicUrbanDensities.pdf

Inn, T. L. (2020). Smart city technologies take on COVID- I9. Penang Institute Issues (working paper). Accessed at https://penanginstitute.org/wpcontent/uploads/2020/03/27_03_2020_TLI_download.pdf

Jacobs, J. The Death and Life of Great American Cities. New York: Random House.

Jeffres, L. W., Bracken, C. C., Jian, G., \& Casey, M. F. (2009). The impact of third places on community quality of life. Applied Research in Quality of Life, 4(4), 333. Accessed at https://engagedscholarship.csuohio.edu/cgi/viewcontent.cgi?article=10 I \& context=clcom facpub

Klinenberg, E. (200I). Dying alone: The social production of urban isolation. Ethnography, 2(4), pp. $50 \mathrm{I}-53 \mathrm{I}$.

Klinenberg, E. (2013. Adaptation: How can cities be climate-proofed? The New Yorker, January 7 2013. Accessed at https://www.newyorker.com/magazine/2013/0 //07/adaptation-eric-klinenberg

Kotkin, J. (2020). "Angelenos like their single-family sprawl. The coronavirus proves them right." Los Angeles Times, April 26, 2020. Accessed at https://www.latimes.com/opinion/story/2020-0426/coronavirus-cities-density-los-angeles-transit

Lefevbre, H. (1974). The Production of Space. Oxford: Blackwell.

Litman, T. (2020). Pandemic-Resilient Community Planning. Victoria: Victoria Transport Policy Institute. Accessed at https://www.vtpi.org/PRCP.pdf

Mehaffy, M. (20I2). The real reason cities can be so much greener than other places. CityLab (February 22, 2012). Accessed at https://www.citylab.com/life/2012/02/real-reason-cities-can-beso-much-greener-other-places/I293/

Mehaffy, M. (20I5). Urban form and greenhouse gas emissions: Findings, strategies, and design decision support technologies. Delft: Delft University of Technology.

Mehaffy, M., Elmlund, P. and Haas, T. (2019). Public spaces and private conflicts in the New Urban Agenda. WIT Transactions on Ecology and the Environment, 238, pp. 87-96. Accessed at https://www.witpress.com/Secure/elibrary/papers/SCI9/SCI9008FUI.pdf

Mehaffy, M. and Salingaros, N. (2017). Design for a Living Planet: Science, Settlement, and the Human Future. Portland: Sustasis Press.

Roche, M. P. (20/9). Taking Innovation to the Streets: Microgeography, Physical Structure and Innovation. Review of Economics and Statistics, I-47.

Rocklöv, J., \& Sjödin, H. (2020). High population densities catalyse the spread of COVID-19. Journal of Travel Medicine, 27(3), taaa038. Accessed at https://academic.oup.com/jtm/article/27/3/taaa038/58077/9? casa token=70 lyBeWLUAAAAA:NISMCbZI6d52lyheRKssHDsdeVZvowyYzVmTGR_v4KH5IVvPFdMEFmEQK2B Loc7Zb6Swzw7eM-pF

Soja, E. (1996). Thirdspace: journeys to Los Angeles and other real and imagined places. Cambridge, Mass: Blackwell.

Stier, A., Berman, M., \& Bettencourt, L. (2020). COVID-I9 attack rate increases with city size. Mansueto Institute for Urban Innovation Research Paper. Accessed at https://arxiv.org/pdf/2003.10376.pdf

Urban Task Force (1999). Towards an Urban Renaissance. London: Routledge. 